\title{
Aprender pensando sobre a própria vida - Um ateliê biográfico na formação de educadores/professores
}

\author{
Learning to think about one's life - A biographical workshop \\ in the formation of educators/teachersAbstract
}

\author{
Conceição Leal da Costa', Constança Biscaia², Andrés Argüello Parra ${ }^{3}$
}

\section{Resumo}

Neste texto assumimos o quadro da pesquisa biográfica em Educação e a corrente das histórias de vida em formação, incluindo alguns estudos atuais neste campo. Partilhamos vivências, práticas e reflexões em torno de um ateliê biográfico de projeto (ABP) gerado e desenvolvido com onze estudantes durante o atual ano letivo, no período final da formação inicial de educadores/professores. Apresentamos os contornos do modelo de formação deste recente perfil profissional em Portugal, o processo associado à conceção do dispositivo pedagógico em si e como se tem desenvolvido em articulação com a concretização do Curso de Mestrado em Educação Pré-escolar e Ensino do $1^{\circ}$ Ciclo na Universidade de Évora. Sustentando o ABP e testemunhando curiosidades e interesses iniciais, descortinamos algumas questões que nos moveram em busca de caminhos de construção de identidade(s). Para tanto, destacamos os conceitos de aprendizagem biográfica e de biographicity (Alheit \& Dausien, 2000; Alheit, 2009) ou biograficidade em Delory-Momberger (2016), assim como o de ateliê biográfico de projeto proposto por Delory-Momberger (2006). Porque estamos na fase final, as considerações finais são narrativas emergentes de como em conjunto temos aprendido pensando sobre a própria vida. Terminamos sem concluir. Das releituras das narrativas biográficas escritas e das conversas que mantivemos nos momentos de encontro e partilha, anunciamos alguns aspetos onde ressalta $(\mathrm{m}) \mathrm{o}(\mathrm{s})$ desejo $(\mathrm{s})$ de ser educadora/professora em diferentes nuances e com voz. Advogamos que convocam reflexões sobre múltiplas identidade(s) em construção tendo em conta o processo, o contexto, o conhecimento e as pessoas em formação. Acompanhar e refletir em momentos de formação profissional universitária, pode ser um caminho que deixa carrilar projetos (d)e vida e identidades que se (re)constroem transgredindo posições e fomentando disposições. Palavras chave

Pesquisa biográfica, narrativas, formação de educadores/professores, aprendizagem, identidade.

\section{Abstract}

In this article, we assume that the biographical research is about how people's life courses develop through interaction between the individual subjectivity and the societal conditions. We share experiences, practices and reflections around a biographical project atelier (ABP) developed with eleven students during the current school year, in the final of their teacher education. We present the model of this recent teacher profile in Portugal for early years, the process and the design of the pedagogical device itself and how it has been developed within Master Course in Pre-school Education and $1^{\text {st }}$ Cycle at the University of Évora. Because learning is an important part of this interaction, and therefore biographical research includes a conception of learning. For this, we provide an overview of the theoretical understanding of learning in a biographical perspective. Biographical learning and biographicity (Alheit \& Dausien, 2000; Alheit, 2009) or biograficity in Delory-Momberger (2016), as well as the biographical project atelier proposed by Delory-Momberger (2006) were the most important concepts. The final considerations are emerging narratives of how together we have learned thinking about life itself. We finished without finishing. From the re-readings of the written biographical narratives and the conversations we had in the moments of meeting and sharing, we announced some aspects where the desire (s) of being an educator/teacher in different nuances and with voice is stressed. We advocate calling for reflections on multiple identity (s) under construction taking in to account the process, the context, the knowledge and the people. Accompanying and reflecting in moments of teacher education the university can be a path that allows projects, life and identities that are (re) constructed transgressing positions and fostering dispositions.

\section{Keywords}

Biographical research, narratives, teacher education, learning, identity.

\footnotetext{
Conceição Leal da Costa. Universidad de Évora (Portugal), mclc@uevora.pt.

2 Constança Biscaia. Universidad de Évora (Portugal), cbiscaia@uevora.pt.

3 Andrés Argüello Parra. Universidad Pedagógica y Tecnológica (Colombia), jaime.arguello@uptc.edu.co.
} 


\section{"Signifier vitalement une vie est un acte vital de création, de co-création de traits d'union entre soi et la vie, celle des autres et celle du monde. C'est un acte de naissance, de co-naissance, signant peut-être l'aboutissement ultime d'une des derniè- res étapes métamorphosants de l'existence».}

(Gaston Pineau, 2012: 184)

\section{Introdução}

Neste texto assumimos o quadro da pesquisa biográfica em Educação (Delory-Momberger, 2016) e a corrente das histórias de vida em formação (Pineau \& Legrand, 2007) sem olvidar alguns desafios e avanços atuais destas abordagens (Breton, 2018). Partilhamos vivências, práticas e reflexões em torno de um trabalho com enfoque na dimensão pessoal da construção identitária de futuros docentes e que denominámos por ateliê biográfico de projeto (ABP). Foi gerado e desenvolvido no período final de uma formação inicial de educadores/professores e por tal apresentamos os contornos do modelo de formação deste recente e provocatório perfil profissional em que se integrou. Explicamos o processo associado à respetiva conceção do ABP, o dispositivo pedagógico em si e respetivo desenvolvimento, ao mesmo tempo que identificamos os princípios teórico-metodológicos que assumimos neste projeto que se quis participado, de auto e hétero-formação e que está em fase de conclusão, mas ainda não terminou.

Consideramos que o contexto e o lugar de onde falamos e onde o processo decorre, assim como interesses profissionais e no domínio da investigação nunca são indiferentes. Por isso, esclarecemos que este ABP foi realizado em Portugal, mais propriamente na Universidade de Évora, com duas docentes e onze futuras educadoras/professoras em estágio, ou seja, durante um ano letivo e coincidente com os momentos de conclusão do Mestrado em Educação Pré-escolar e Ensino do $1^{\circ}$ Ciclo do Ensino Básico. Mais adiante explicitamos as questões iniciais que nos moveram e explicitamos que falamos de um curso profissionalizante, isto é, um percurso de formação inicial obrigatório para o respetivo exercício da profissão. Neste momento, é apenas frequentado por mulheres nesta universidade e com isto aproveitamos para justificar a linguagem que muitas vezes aqui utilizamos no feminino, mas também que quando a utilizamos no masculino é, tão só, para simplificar a exposição escrita ao longo do texto.

A redação por três autores ${ }^{4}$, quando apenas as duas primeiras têm estado diretamente envolvidas exige também alguma justificação. Os primeiros tópicos deste artigo colheram vários contributos de estudos nacionais e internacionais ${ }^{5}$, mas foram igualmente importantes os olhares do último autor enquanto docente

4 As autoras são docentes da Universidade de Évora e só a primeira faz parte da equipa docente no Curso de Mestrado em Educação Pré-escolar e Ensino do $1^{\circ}$ Ciclo. A primeira tem responsabilidades na coordenação do programa de formação, pertencendo também à respetiva Comissão Executiva de Acompanhamento, fazendo que as reflexões que se apresentam representem um caminho reflexivo feito em equipa naquele âmbito.

A segunda autora é Doutora em Psicologia da Educação e psicoterapeuta. Atualmente é docente nos cursos de formação de psicólogos, terapeutas e enfermeiros da Universidade de Évora, mas exerceu a docência na formação de professores durante um longo período da sua carreira. Os interesses académico e profissional de ambas, focam-se na aprendizagem e desenvolvimento profissional e a investigação que têm desenvolvido no âmbito das histórias de vida tem sido, sobretudo, realizada em conjunto. Não se estranhe, portanto, que se formasse uma equipa que moveu a Educação e Psicologia, o que também se explicita no texto que é nossa intenção dar continuidade a este projeto na formação de educadores/professores, mas alargá-lo à formação de outros profissionais do cuidar (e) do desenvolvimento humano, nomeadamente da Saúde.

Realizou aulas abertas à comunidade académica e conferências, organizadas com a primeira autora, nas quais estudantes e nós docentes, e outros, participaram. Este aspecto não foi de somenos importância, pois foi a reflexão e o debate que nos foram permitindo conhecer, compreender e apropriar de processos sucessivamente. Uma consciencialização progressiva, (re)construtora de sentidos, foi dando origem a várias questões. Por isso, dizemos que foi um projeto consentido para o qual todos os participantes puderam contribuir ao longo do (seu) tempo.

Para melhores esclarecimentos pode ler-se o que hoje encontramos sobre avanços no que se pensa sobre possíveis alcances da pesquisa biográfica. É o caso da emergente ideia de uma possível construção de especificidades epistemológicas de «Ciências da Formação», assim designadas, por exemplo em Botinet (2017).

5 Este artigo é um produto dos projetos de investigação em rede de networking, em especial da Rede Internacional de Ensino Superior e da Rede de Pesquisa biográfica, nomeadamente da BIOGraph em que se integram também. 
e investigador. Interessado na formação de professores e visitante na Universidade de Évora, fez nesse âmbito alguns momentos de observação participante em sala, onde as estudantes agora participantes no ABP marcavam presença e também fez algumas rodas de conversa. O seu olhar esclarecido e crítico ofereceu válidos contributos acerca deste percurso e também sobre o alcance metodológico e epistemológico da pesquisa biográfica em Educação ${ }^{6}$.

Acrescentamos que os três, enquanto investigadores e docentes empenhados na formação de professores e também na de outros profissionais do cuidado e do desenvolvimento humano, afirmamos o valor epistemológico e formativo das histórias de vida. Permanecemos alinhados com autores como Clandinin \& Connelly (1995), Alheit (1999); Alheit \& Dausien (2000); Clandinin (2000), Josso (2002); Pineau \& Legendre (2007); Delory-Momberger (2012), Passeggi \& Souza (2017), entre muitos outros ${ }^{7}$. Numa referência à investigação que temos realizado e sobre o que pensamos acerca da formação que promovemos na Universidade de Évora (Leal da Costa, 2015; Folque Leal da Costa \& Artur, 2016; Leal da Costa \& Nunes, 2016; Leal da Costa \& Cavalcante, 2017) tem-nos movido a ideia que «no procedimento de formação pelas histórias de vida, a narrativa é uma preliminar» (Delory-Momberger, 2006: $363)$.

Impeliram-nos curiosidades e interesses sobre como as narrativas biográficas poderiam enriquecer este percurso formativo concreto, pois tínhamos algumas questões de partida: um ABP permitir-nos-ia acompanhar momentos de profissionalização que deixam carrilar projetos de vida e identidades que se (re)constroem? Conhecer caminhos da construção e do desejo de se ser educadora / professora? Qual é a atenção dada à pessoa nesta trajetória profissionalizante? Qual o nosso papel como docentes da universidade e formadores de professores nestes processos de formação e quais os nossos contributos para uma construção identitária?

Os conceitos que nos orientaram não foram indiferentes e dedicar-lhes-emos a devida atenção, partilhando e ilustrando o uso e a sua conveniência. Completamos o artigo com considerações a que foi possível chegarmos até hoje, uma vez que este projeto ainda prevê que voltemos a encontrar-nos com as estudantes e que as iniciais narrativas biográficas que escreveram venham a ser reescritas por cada uma delas. Porém, para essa fase final foi planeado mais um momento de encontro que a antecederá, para fazermos releituras do que empreendemos até aqui.

Iniciámos esta última etapa com uma comunicação oral num evento científico sobre formação de educadores/professores na Universidade de Évora ${ }^{8}$. Mas, se foi avisado socializar o que tem sido este ABP e o que nele temos aprendido, pensamos que será a escrita deste texto que pode tornar públicas as vozes de nós todas e assim fazermos o remate deste processo comunicacional com construção de sentidos. Mencionando o autor da epígrafe, Pineau (2012), aspiramos a que um ABP com lugar na formação de educadores/professores possa ser, efetivamente, espaço/tempo de um ato de nascimento, de co-nascimento, de um estágio

6 Realizou aulas abertas à comunidade académica e conferências, organizadas com a primeira autora, nas quais estudantes e nós docentes, e outros, participaram. Este aspeto não foi de somenos importância, pois foi a reflexão e o debate que nos foram permitindo conhecer, compreender e apropriar de processos sucessivamente. Uma consciencialização progressiva, (re)construtora de sentidos, foi dando origem a várias questões. Por isso, dizemos que foi um projeto consentido para o qual todos os participantes puderam contribuir ao longo do (seu) tempo.

7 Para melhores esclarecimentos pode ler-se o que hoje encontramos sobre avanços em possíveis alcances da pesquisa biográfica. É o caso da emergente ideia de uma possível construção de especificidades epistemológicas de «Ciências da Formação», assim designadas, por exemplo em Botinet (2017).

8 Pode compreender-se em http://www.fepue2.uevora.pt/ o que é este evento científico de âmbito nacional até esta edição, organizado pelas Comissões Executivas de Acompanhamento destes cursos profissionalizantes e realizado de dois em dois anos. A próxima edição, dada a aceitação e a projeção do que se tem vindo a fazer na Universidade de Évora e do nosso trabalho em redes de networking, será internacional. 
de metamorfose da existência e, ao mesmo tempo, sirva o propósito de ser um caminho significativo porquanto todos os que nele participamos, (re)construímos narrativas e aprendemos pensando sobre a própria vida.

\section{Um atelier biográfico na formação de educadoress/professores - Razões e opções}

Neste artigo não cabe discutirmos os desafios que são hoje lançados às escolas aos professores e à sua formação, mas na verdade é de inovação, de mudança paradigmática do que é ensinar crianças e do que é aprender na escola face a posturas tradicionais que também estamos aqui a tratar. Foi a construção identitária de um novo perfil, educador/professor, o maior desafio que nos dispôs a iniciar um ateliê biográfico de projeto (ABP), baseado no conceito de Delory- Momberger (2006), desenvolvido num percurso de formação inicial para a docência e perseguindo a ideia que ao formar o profissional há que lembrar a pessoa. A estes aspetos deveremos juntar que o profissional que preparamos não é alheio a uma epistemologia da profissão de educador de infância e de professor do $1^{\circ}$ Ciclo, em Portugal muito diferentes entre si. Tornar-se educador/professor é, também por isso, construir uma identidade antes inexistente, assim como contrariar lógicas fragmentárias na cultura da escola e preponderâncias disciplinares. É gerir e desenvolver o currículo assumindo-se um profissional altamente qualificado ${ }^{9}$ e monodocente.

Citando um texto anterior, evidenciamos algumas preocupações nesse sentido, confirmando que não são de agora:

«Numa sociedade em constante mudança, o conbecimento aumenta exponencialmente e encontra-se
acessivel por via das novas formas de comunicação. Existem novas formas de trabalho, crescentes
desigualdades e fragmentaçoes (sociais, económicas e culturais) e o papel do professor, bem como a sua
formação têm sido objeto de questionamentos. Nestes tempos, em que profissão docente é considerada
complexa, as condiçôes do seu exercício são exigentes perante transformações tão céleres, a valorização
da visão holística, ecológica contextualizada dos processos de aprendizagem e de desenvolvimento pro-
fissional tem reforçado que todos os processos formativos, iniciais, contínuos, formais ou informais, in-
fluenciam mudança dos professores consequente transformação dos seus contextos de trabalho. (...). A
influência da formação inicial, na pessoa e profissional em permanente construção, exibe a importância
(....)». (Folque, Leal da Costa \& Artur 2016: 179-180).

Em busca de resposta para questões que abarcam a complexidade do ser humano, assumimos o poder da narrativa, não apenas como produto de um «ato de narrar», mas que «ela tem também um poder de efetivação sobre o que ele narra» (Delory-Momberger, 2016: 141). Estamos conscientes que um longo tempo como alunos dificulta que nos tornemos profissionais inovadores e (re)construtores das imagens de professor e de escola que fomos construindo ao longo do tempo. Assim, há algum tempo que manifestamos preocupação com a ausência de uma atenção focada na pessoa que se torna educador/professor. Simultaneamente, estamos conscientes que uma profissionalização organizada no formato de curso mostra vicissitudes e limites que buscamos ultrapassar. Mas neste contexto não se dissimulará a visão projetiva de cada estudante? Permitir-se-á o diálogo do seu ser interior com o exterior no espaço/tempo do curso? Sabendo que «a história de vida não é a história da vida, mas a ficção conveniente pela qual o sujeito se produz como projeto de si mesmo» (Delory-Momberger, 2006: 365), o ABP poderia ser a oportunidade de fazer acontecer a mudança. Permitir-nos-ia vislumbrar a construção singular que cada estudante tem vindo a fazer da sua existência e da experiência no espaço/tempo da formação profisionalizante. Ou seja,

\footnotetext{
9 Para o exercício da docência em qualquer nível de ensino, desde a educação Pré-escolar até ao final do ensino Secundário e com exceção para o Ensino Superior, é necessário o grau de mestre.
} 
poderíamos em linha com o que estuda a pesquisa biográfica e o saber que pretende alcançar, «tomar em conjunto o que constitui precisamente a interface que ela se propõe a analisar e compreender: ao mesmo tempo, a agentividade individual e a estrutura social, a experiência singular e os "quadros da experiência", a "sociedade vivida" e a "sociedade constituiída"» (Delory-Momberger, 2016: 141). Contando a nossa história ou contando-a a alguém vamo-nos dando conta da nossa historicidade como pessoa, agindo e interagindo no mundo da vida. Esse aspeto parece-nos claro em Alheit (2009): «life constructions extend beyond what we narrate about our lives. They are hidden references to the structural conditions that impose on us» (p. 143).

Assim, no trabalho projetivo do ABP orientaram-nos alguns conceitos preliminares. O primeiro, cuidar (d)a pessoa em formação, que é um aspeto há muito considerado pela pesquisa biográfica em Educação. Em nosso entender é extremamente necessário, mas dificilmente conseguido quando o queremos perceber relacionado com um conceito de identidade profissional que tem a pessoa muito presente. A identidade aparece aqui como uma entidade plural, um sistema multidimensional, que engloba diferentes identidades resultantes das interações que o indivíduo estabelece nos diferentes espaços da vida em que se vai inserindo e entendendo. Simultaneamente, que tais dimensões não se limitam a estar juntas, mas que se organizam num todo, que pode ser mais ou menos estruturado. Esta ideia leva-nos, no fundo, a compreender o lado mais pessoal da formação e da identidade profissional em linha com autores como Abraham (1982, 1989), Nóvoa (1992; 2004) ou com Hall (2006).

Sequencialmente, este trabalho implicou alguns conceitos que permanecem na atualidade dos trabalhos em pesquisa biográfica e na corrente das histórias de vida em formação - entender que é no ato de contar que nos instituímos, permitindo uma construção identitária:

«Durante o ato da narrativa, o sujeito se configura segundo uma hipótese de si mesmo que advém da multiplicidade de possibilidades que constituem seu horizonte e que ele toma provisoriamente como aceitável on 'suficientemente boa'. Dižer, do sujeito, que ele é uma hipótese é dizer que ele permite instituir provisoriamente uma figura de si, submetida à validação da experiência. Por meio da sucessão $e$ da diversidade das experiências, o sujeito- hipótese testa e experimenta a validade de sua construção identitária e a reconfigura sob medida». (Delory-Momberger, 2006: 364).

A pertinência, a profundidade e tudo o que implica sustentar e orientar o desenvolvimento de um ABP com este alinhamento, exige explicitar mais alguns conceitos de que nos socorremos. É o caso de aprendizagem biográfica (Alheit, 2009), de biographicity (Alheit \& Dausien, 2000; Alheit, 2009) ou biograficidade na expressão de Delory-Momberger (2016).

Acreditando que teríamos pela frente um trabalho de re-significação de sentidos «que questionava, de um ou de outro modo, toda a nossa acção como educadores» (Nóvoa, 2004: 20), impregnámo-nos de vontades para fazer acontecer uma pedagogia que cumprisse esse desígnio - o ABP. Entre outras inspirações, apoiámo-nos em reflexões de autores que nos permitiram enquadrar o ABP, ao mesmo tempo assumido como a possibilidade de escutar e ser escutado, em linha com o isomorfismo pedagógico ${ }^{10}$ que almejamos (Leal da Costa \& Folque, 2013; Folque, Leal da Costa \& Artur, 2016) e considerando que não

10 Por isomorfismo pedagógico entendemos [...] a estratégia metodológica que consiste em fazer experienciar, através de todo o processo de formação, o envolvimento e as atitudes; os métodos e os procedimentos; os recursos técnicos e os modos de organização que se pretende que venham a ser desempenhados nas práticas prossionais efetivas dos professores. (Niza, 2009: 352). 
temos conseguido abranger esta dimensão transformadora de si e dos outros incorporando a história da vida. Como Nóvoa (2004), reivindicamos necessidades de

«(...) práticas de auto-formação, da construção de narrativas sobre as nossas próprias histórias de vida pessoal e profissional. Estou a falar dessa necessidade de cada um se contar a si próprio como modo de adquirir uma maior consciência do seu trabalho como educador».

"(...) "empowerment", essa palavra complexa da lingua inglesa que no Brasil tem sido traduzida por "apoderamento" ou "empoderamento" - um reforço de poder tão necessário para os professores e, em particular, para os professores principiantes, nessa fase decisiva da vida profissional em que são lançados para as situações mais dificeis, muitas vezes sem qualquer apoio».

"(...) necessidade de elaborar um conhecimento pessoal (um auto-conbecimento) no interior do conbecimento profissional e de captar (de capturar) o sentido de uma profissão que não cabe apenas numa matriz técnica ou científica. Toca-se aqui em qualquer coisa de indefinivel, mas que está no cerne da nossa identidade profissional. Estou absolutamente convencido que sem um novo olhar teórico sobre esta problemática dificilmente conseguiremos abrir os caminhos de futuro da profissão docente». (p. 22).

Nesta busca, o valor inestimável da narrativa para a compreensão do ser humano e do seu desenvolvimento torna-se evidente. Tecemos em variados contextos e lugares, muitas e diversas «narrativas para dar sentido ao acontece e ao que nos acontece. De igual modo, vamos nos tecendo com elas e por elas» (Passeggi, 2016: 305). Estas afirmações pressupõem uma valorização da linguagem como estruturante do pensamento (Vygotsky, 2001) e, consequentemente, do que se pode entender o que é aprender. Neste mesmo sentido, a nossa forma de ver, de estar e de ser no mundo também não podem ser entendidos independentes da linguagem. O valor heurístico da narrativa manifesta-se, tornando-se igualmente um bom ponto de partida para explicações sobre a natureza e/ou a existência humana.

Passeggi (2016) justifica o progressivo interesse de diferentes áreas do saber pelas narrativas, permitindo sustentar as nossas opções pedagógicas na proposta de um ABP num processo de profissionalização para a monodocência com crianças:

"Como já propunha Vygotsky (2001), "o pensamento não se expressa, mas se realiza na palavra", pois ao transformar-se em linguagem ele se se reestrutura e se modifica. Assim, entendendo-se a linguagem como fator estruturante das visões de mundo, do modo de perspectivar a realidade, como sugere Tomasello (2003), os pesquisadores passam a se debruçar sobre crenças, representações, valores, mediante os quais o bumano dá sentido à vida. E, mais ainda, a linguagem não só estrutura 0 pensamento, mas se impõe como ação no mundo, conforme demonstram os estudos da pragmática. No célebre livro, Quando dizer é fazer, Austin (1990) chama a atenção para os atos performativos e a força da linguagem como ação criadora de realidade no mundo. Dai a importância de se compreender melhor a relação entre pensamento, linguagem e práxis social». (p.305).

No que diz respeito ao dispositivo propriamente dito, pedagogicamente utilizado na perspetiva de uma formação holística, integrado e integrador em momentos de preparação para a docência, o ABP pode ser visto como um espaço/tempo de encontro e reflexão e a narrativa entendida como «uma das formas privilegiadas de atividade mental e reflexiva segundo a qual o ser humano se representa e compreende a si mesmo no seio de seu ambiente social e histórico» (Delory-Momberger, 2006: 369). Continuando com a autora, acreditamos que num ambiente cuidado e que reconhece a vida como experiência formadora e de formação, as narrativas biográficas das futuras educadoras/professoras «não advêm do controle do 
'ser interior' considerado em si mesmo e para si mesmo, mas advêm da forma histórica e socialmente construída que o relato permite dar às experiências individuais» (p. 369).

Delory-Momberger (2006) explicita claramente ideias essenciais sobre o para que forma a narrativa. Reivindicamo-las para melhor fundamentar o que cremos serem as possibilidades formativas do ABP:

"As histórias de vida não formam nada além da formabilité, isto é, da capacidade de mudança qualitativa, pessoal e profissional, engendrada por uma relação reflexiva com a sua 'bistória' considerada como 'processo de formação' (Dominicé, 1990). A capacidade de mudança (a formabilité), postulada pelos procedimentos de formaça mediante as histórias de vida, repousa no reconhecimento da vida como experiência formadora, e da formação como estrutura da existência (Honoré, 1977; 1990). O procedimento de formação consiste em trabalhar sobre as representações que os formandos dão nos relatos de suas experiências de formação, reinscrevendo-as na perspectiva de um projeto». (p. 366).

Objetivando o ateliê que expomos, numa perspetiva de socialização da formação, de uma pedagogia que desvenda aprendizagens, desconstrói preconceitos e dá contributos para a construção de uma identidade, incorporando a pessoa que está a tornar-se educadora/professora, este trabalho com narrativas biográficas pressupôs, efetivamente, que a aprendizagem é um processo de desenvolvimento humano. Nesse sentido, a ideia de biografiração como objeto de estudo esteve igualmente presente, entendida como sinónima de busca da compreensão de como nos tornamos quem somos.

Tendo em conta o percurso já percorrido no ABP, podemos desvendar encontros entre entendimentos de aprender na perspetiva biográfica, com outros entendimentos. Num confronto com perspetivas em que a aprendizagem (profissional) é assumida como uma atividade culturalmente mediada, historicamente desenvolvida que emerge da atividade prática (Engeström, 2001), ou, nesta mesma linha, em que aprender é entendido como um processo de transformação pessoal e social, fazer emergir a dimensão auto e hétero formativa das narrativas e integrar essas dimensões na formação inicial de educadores/professores afirma um sentido desse encontro - falamos pois de busca do desenvolvimento humano. Isto não deixa esquecer que, afinal, a aprendizagem biográfica em certa medida também enraíza numa matriz histórico-cultural. Passeggi (2011), ao afirmar que «hemos buscado apoyo en la perspectiva histórico-cultural, en los trabajos de Vygotsky $(1989,1991,1999)$, en el interaccionismo sociodiscursivo desarrollado por Bronckart (1999) y en la psicología cultural propuesta por Bruner (1989, 1991, 1995, 1997, 1998, 2001, 2005), que ofrecen contribuciones pertinentes sobre el papel de las narrativas en el desarrollo humano». (p. 30), ajuda-nos a compreender porquê.

Por seu turno, o ABP justificou-se quando entendemos que «a dimensão de projeto é constitutiva do procedimento de formação, na medida em que ela instaura uma relação dialética entre o passado e o futuro e em que ela abre à pessoa em formação um espaço de formabilité» (Delory-Momberger, 2006: 366). Estes são referenciais que robustecem a ideia de que a aprendizagem biográfica foi perspetivada de maneira coerente com objetivos deste curso da Universidade de Évora. Autores como Delory-Momberger (2005, 2006, 2016) Alheit (2009) ou Alheit e Dausien (2000) definiram biografização e biograficidade, conceitos que nos ajudaram a fazer várias opções fundamentadas. Por tal, passamos a esclarece-los inscrevendo-os num entendimento de aprendizagem ao longo da vida que também não foi indiferente.

Estes autores «interrogam não apenas a capacidade do ser humano de narrar uma história qualquer, mas também a capacidade de fazer a narração de sua própria vida, o que denominam de biografização, entendida como uma atividade mental, cognitiva pela qual o humano organiza narrativamente a experiência 
vivida» (Passeggi, 2016: 306). Esta é uma leitura que comungamos, permitindo afirmar que «ganha força a afirmação de Bruner quando propõe que "a criação do eu é uma arte narrativa", portanto um ato performativo, autopoiético pelo qual narrar-se é (re)inventar-se» (Passegi, 2016: 306).

Encontrámos em palavras de Alheit (2009) uma certa curiosidade: «lifelong learning 'instrumentalises’ and 'emancipates' at one and the same time» (p.138). Esta visão particular de biographical learning, uma micro-perspetiva, como a denomina o autor, permite compreender a aprendizagem no tempo da vida, clarificando, mas sobretudo sustentando, o que entendemos no contexto do APB que é a aprendizagem biográfica e os respetivos contributos transformadores de si, dos outros e dos contextos que um processo de biografização encerra num trabalho destes com futuros educadores/professores que se encontram periodicamente para refletir e conversar sobre a formação e sobre o profissional que se preparam para ser. E foi assim que nos orientámos para um ateliê biográfico de projeto (Delory-Momberger, 2006), permitindo-nos fundamentar epistemológica e metodologicamente este dispositivo pelas histórias de vida.

Por fim, mas não por último, não podemos esquecer o modelo de formação de educadores/professores em que se integra um ABP, nem tão pouco ignorar tratar-se da formação para um perfil profissional que é novo, quer no horizonte temporal da formação docente em Portugal, quer da epistemologia da profissão. Assim, também focamos a emergência de necessidades e interesses, nossas e das estudantes, invocando contornos concetuais determinados pelas próprias características deste curso. Constatámos que para além das determinações legais de âmbito nacional, uma duração de dois anos, precedida de três (uma Licenciatura em Educação Básica), evidencia-se na Universidade de Évora uma busca de coerência e de cuidado com processos transacionais, com base em princípios e fundamentos idênticos no total dos cinco anos. Nesta análise confirmámos a forte presença de uma matriz sócio-cultural, sobretudo quando atentamos para orientações pedagógicas sobre formação, aprendizagem, ou desenvolvimento profissional.

Portanto, não foi indiferente, nem poderia ser, o que entendemos por aprendizagem neste ABP nem sobre a sua relação com conceitos mais amplos como qualidade na educação escolar com crianças, aprendizagem ao longo da vida, ou sobretudo, por identidade profissional e por monodocência. O recurso à narrativa com um grupo de futuras educadoras/professoras, perseguindo uma perspetiva biográfica, buscou garantir tais lógicas de coerência na pesquisa e na formação globalmente, pelo que demos uma especial atenção ao escutar a pessoa e profissional em formação na sua totalidade. Assim, nenhuma das opções expostas condicionou o desenvolvimento do ABP limitando-o a alguma uma configuração pedagógica que não permitisse a participação e a negociação com as estudantes de como, com quem, quando e para quê nos iriamos encontrar.

Para tanto, valeram-nos alguns conceitos organizadores do nosso papel. E orientadores do trabalho nos encontros com as estudantes. Destacamos o de mediação biográfica enquanto modo específico de acompanhamento, numa ótica da investigação biográfica e inspirado em pressupostos de Vygotski, pois foi fundamental. Entendeu-se ser uma «actividad práctica, que puede ser ejercida por el formador, en las más diversas áreas del conocimiento (...), con el propósito de provocar cambios deseables para la persona en formación y deseadas por el sujeto. (...) Por ser formativa, la intención de formar (se) es guiada por el coemprendimiento del formador y de quien se forma» (Passeggi, 2011: 37). Assim, demos sentido aos papéis diferenciados que assumimos no ABP, esbatendo assimetrias entre docentes e estudantes, assumindo o poder da participação, da conversa e do feedback reflexivo. 


\section{Narrativas (d)e curso}

\section{"Que o acto de ensinar se torne a caixa \\ de ressonância de todo o nosso sern.}

(Sylvia Ashton-Warner)

Admitindo que um percurso profissionalizante pode ser também uma trajetória de formação e de construção identitária, podemos entender que se constitui como caminho que cada um traça a partir das vivências anteriores, da sua experiência enquanto aluno, enfim, das mais variadas especificidades da sua caminhada até então. Em muitos estudos e autores perpassa a ideia de que o professor ensina como viu ensinar. Torna-se então, absolutamente necessário, criar espaços no contexto da formação inicial para explicitar essas crenças dos futuros professores, para que ocorra uma reflexão e questionamento fundamentado sobre o processo de se tornar professor enquanto ainda não o é (Flores, 2010).

Nesse sentido, refletir sobre a trajetória de quem se torna educador/professor, sobre relações de alteridade estabelecidas com os outros, com os saberes ou com o mundo, torna-se basilar para compreendermos a identidade, enquanto processo e diferentes nuances. E é sobre esse processo de mudança de si, aqui pensado no âmbito de uma formação inicial para a docência que este artigo se debruça, apresentando uma reflexão em que o conceito de identidade deve ser esclarecido e enquadrado no contexto global de um projeto (modelo) de formação, entendido como um percurso académico que deve preparar cada estudante para a monodocência com crianças entre três e dez anos de idade.

Para o efeito, e de acordo com Hall (2006), destacamos que um aspeto relevante da construção identitária é o facto de os sujeitos assumirem diferentes identidades em diferentes circunstâncias e momentos. Assim, a identidade apresenta-se como um processo que se vai estabelecendo na interação entre a busca do eu e a busca de uma cultura. Por sua vez, as marcas identitárias encontram-se em itinerários de relações e interações com os outros, em tensões e diálogos mediados pela linguagem e pela cultura.

Neste alinhamento concetual, não podemos ficar indiferentes a momentos, vivências, contextos, encontros ou conhecimentos que, ocorrendo durante um período de profissionalização na universidade, insinuem lógicas fragmentárias na construção dos saberes, ou dissociem a identidade individual de outros espaços e tempos da vida mais amplos, ou mesmo do tempo histórico em que ela acontece. É nossa convicção que, lidar com a inteireza da pessoa em formação, é proporcionar-lhe oportunidades de elaboração de olhares críticos, não só sobre a própria identidade, memória, cultura e formação, mas sobre o mundo, sobre o outro, sobre a cultura e sobre a realidade em que estão inseridos. No fundo, preparar cada um para se tornar educador/professor e, simultaneamente, ter em mente que se trata de uma caminhada da pessoa (e futura) profissional que se forma para uma intervenção sustentada e autónoma, agente local nas múltiplas realidades que uma profissão complexa e com crianças lhes irá exigir num futuro próximo. No fundo, implicou o alinhamento com ideias de Lipiansky et al., (1990), reconhecendo a liberdade de ação dos atores sobre determinismos sociais e biográficos. Uma possibilidade de estratégias identificatórias enquanto procedimentos implementados de forma (consciente ou inconsciente) «par um acteur (individuel ou collectif) pour atteindre une, ou des, finalités (définies explicitement ou se situant au niveau de l'inconscient) procédures élaborées em fonction des diferentes déterminations (sócio-historiques, culturelles, psychologiques) de cette situation» (p.24). 
Relendo os objetivos da formação de educadores/professores na Universidade de Évora ${ }^{11}$, em cuja projeção colaborámos desde a criação do curso, destacamos que, em boa medida, remetem para aprendizagens nos domínios científico e praxiológico, promissoras de intervenção na ecologia da infância, especialmente no que respeita à educação de qualidade de crianças nas primeiras idades e em ambiente escolar. Para tal, acautela-se que a preparação destes profissionais deverá proporcionar e viabilizar atitudes reflexivas e investigativas, comprometidas com contributos futuros para a inovação de âmbito pedagógico e das práticas educativas com crianças daquelas faixas etárias (Folque, Leal da Costa \& Artur, 2016). Contudo, apesar do nosso envolvimento em múltiplas determinantes do curso, não vislumbramos, nos seus objetivos, indícios de compromissos ou possibilidades efetivas de aprendizagem e construção de conhecimentos que apontem para uma (re)configuração da profissão poder acontecer dentro deste curso contando com a voz das estudantes e uma escuta consequente. No fundo, não encontramos nos objetivos do curso nem na sua estrutura normativa, qualquer necessidade explicita de cuidar da pessoa em formação. E isso premeia este texto com algumas notas sobre o porquê destas afirmações, ao mesmo tempo que justifica a paulatina construção da ideia e de emergentes necessidades de um ateliê biográfico com as estudantes, nesta formação com tantas especificidades. Por outras palavras, julgamos cada vez mais necessário que falar de construção identitária pressuponha cuidar da autonomia, da escuta, das interações ou de contrariar fragmentações, assumindo que a história da vida de cada um de nós se desenvolve no seio de uma rede de relações, em contextos onde age, reage e interage.

Neste alinhamento, tem-se tornado cada vez mais evidente que formar exige que nós docentes da universidade e formadores de futuros professores, acompanhemos percursos e estejamos atentos aos modos como cada sujeito gere a sua própria caminhada no seio da complexidade e dos lugares, tendo em conta a pessoa que é. No fundo, é preciso mudar alguma coisa.

Tomando a ideia de Josso (2002), requere que a significação de vivências seja consentida, havendo tempo, lugar e gente que possibilite fazer reflexões que traduzam conexões com a vida em comum e integrando a temporalidade da vida que vai construindo a própria experiência de cada estudante em formação. Trata-se, efetivamente, de estarmos atentos a uma lógica individual gerada pela estrutura específica e biografada da experiência, mas rejeitando que isso signifique que a estrutura biográfica determina o processo de aprendizagem. Pelo contrário, concordamos com Alheit (2009) que se trata de uma estrutura aberta, integradora de novas experiências, e que, portanto, cada individuo, e neste caso concreto cada futura educadora/professora, ganhe expressão ao interagir com os contextos escolares e com quem os habita, com os outros e consigo mesma. Falamos, pois, na perspetiva de uma integração individual de experiências novas, assente em experiências pessoais passadas e orquestrada porque elas se tiveram em conta. Como processo social, a aprendizagem possibilita a mudança de si ativamente, implicando participação nas mudanças que ocorrem no seu mundo social. O estágio, período de contacto preferencial com contextos de intervenção, o processo de supervisão é um contributo para tal acontecer, mas evidenciando-se uma construção da profissionalidade ocultando a da pessoalidade (Leal da Costa \& Cavalcante, 2017).

Acrescentamos que ter em conta a natureza biográfica do conhecimento sinónima de um processo de aprendizagem que opera a mudança de si e simultaneamente não deixa os contextos estruturais inalterados, implica que concordemos com os autores que apontam a aprendizagem como processo que acontece dentro de transições e que as promove. Transições que podem ser entendidas como processos de

11 Podem ler-se em http://www.oferta.uevora.pt/mestrados/(codigo)/536 
abdução como refere Alleit (2009). Voltando ao curso de Mestrado em Educação Pré-escolar e Ensino do $1^{\circ}$ Ciclo que enquadrou o desenvolvimento do ABP aqui em análise, entender a aprendizagem desta maneira, faz-nos pensar que o conhecimento produzido pelas estudantes ao longo do curso carece de especial atenção ao seu conhecimento biográfico, na medida em que só é genuinamente transitório se for biográfico também (Alheit, 2009). No seu conjunto, estas considerações sobre processos de aprendizagem, implicam entender que um curso de formação profissionalizante, deveria permitir relações a cada estudante com o mundo da vida de modo a proporcionar a auto-reflexão e a hetero-reflexão. No fundo, uma ecoformação a quem tem muitos anos de vida em ambiente escolar como aluna, ao mesmo tempo que nunca teve contactos com esta figura profissional até há pouco inexistente e também nunca foi professor.

Esta ideia de aprendizagem que presidiu à conceção do ABP, pressupondo que não pode ocorrer exclusivamente dentro do indivíduo, depende da comunicação e interação com os outros e das relações com um contexto social. Neste sentido, a aprendizagem (biográfica) está enraizada em mundos da vida que podem ser analisados como ambientes de aprendizagem (Lave \& Wenger, 1991). Proporcionar a imersão em contextos que permitam redesenhar contornos da vida, reconstruindo significados como atores sociais inseridos em contextos específicos, como é o caso de um percurso académico numa universidade, ou um estágio em ambiente escolar com crianças, é promovermos o que Alheit (2009) designou por biographicity. Por tudo isto, o modelo de um curso profissionalizante que uma universidade concebe e estrutura, bem como a legislação que o configura, são aspetos que devem ser questionados e que nós, refletindo em equipa docente na Universidade de Évora, temos vindo e continuamos a questionar. Por exemplo: será que o modelo de formação respeita uma aprendizagem profissional que acontece dentro e através da história da vida de cada estudante? E enquanto processo interativo e socialmente estruturado, cuida da pessoa ao mesmo tempo que ela se vai tornando educadora/professora no período de duração do curso? As sessões presenciais na universidade em conjunto com a permanência nos contextos, escola do $1^{\circ}$ Ciclo e/ou o Jardim de infância, são ambientes de aprendizagem que servem todos propósitos de uma formação que abarca, realmente, a dimensão da pessoa em formação?

Apesar dos estudos que já realizámos no domínio da aprendizagem, formação e desenvolvimento profissional de professores, Leal da Costa (2015) por exemplo, no que diz respeito à aprendizagem e formação de educadores/professores as curiosidades e as questões são amplas e permanecem no horizonte dos nossos interesses na docência e na investigação. O que conhecemos até agora vem-nos dos estudos sobre e com educadores de infância e/ou professores do $1^{\circ}$ Ciclo do Ensino Básico, ou mesmo sobre a Educação de Infância, sobre criança(s) e infância(s), ou ainda de estudos sobre os professores, o seu pensamento, os que focam a complexidade da docência em geral e com crianças. Sendo assim, as reflexões que temos realizado sobre o educador/professor provêm, porventura, de evidencias empíricas na experiência de formadores deste novo e desafiante perfil, sendo certo que reconhecemos que o pensamento estruturado que fizemos até hoje sobre este assunto é incipiente.

Por sua vez, o estado da arte mostra, efetivamente, que pouco se tem pensado profundamente face ao que há para conhecer no âmbito da complexidade que acompanha a formação e o desempenho destes profissionais monodocentes. Lembramos que podem exercer a profissão como educadores de infância (EI) e como professores no $1^{\circ}$ Ciclo do Ensino Básico (1 $\left.1^{\circ} \mathrm{CEB}\right)$. A nossa visão, manifesta em vários textos, sobre o que pode ser uma formação destes docentes e a investigação realizada com eles, como por exemplo, Leal da Costa e Folque (2013), Couveiro, Leal da Costa e Folque (2015), Leal da Costa \& 
Nunes (2016) ou Leal da Costa \& Cavalcante (2017), apesar de considerarmos ser reduzida, permite-nos elucidar alguns aspetos. Por exemplo,

«Pensando na investigação que os estudantes realizam (...), consideramos que se tem revelado uma oportunidade para acrescentar conbecimentos ao que se sabe sobre o ensino, sobre os professores, sobre a investigação, sobre as crianças e sobre a formação destes educadores/ professores. Como produtores de conbecimento e da (re)construção de saberes em contexto, com alunos reais, entre interações e relações significantes, resolvendo problemas e tomando decisões que entrelaçam teoria e prática, acreditamos que se têm convertido percursos e acontecimentos em processos de mudança. Ao mesmo tempo, os estudantes tornaram-se educadores/professores. Assim, a emancipação e autonomia destes profissionais vai sendo construida com os próprios, enquanto membros de uma equipe alargada no tempo do curso, quando as interações e a cooperação para tal contribuem». (Leal da Costa \& Nunes, 2016: 123).

Atrevemo-nos a constatar que os variados trabalhos e atividades, textos e diálogos entre a equipa docente, com docentes cooperantes, estudantes e ex-estudantes ou com outros investigadores, as reuniões, comunicações e eventos científicos que organizamos e/ou participamos partilhando muito do que fazemos na Universidade de Évora e com as escolas, em boa medida têm conduzido a várias narrativas da formação inicial de educadores/professores na Universidade de Évora (Leal da Costa \& Folque, 2013; Folque, Leal da Costa \& Artur, 2016; Leal da Costa \& Nunes, 2016; Folque, Aresta \& Melo, 2017; Folque, 2018, entre outros). Aliás, a relação que mantemos com a Cidade e o papel que lhe atribuímos não é indiferente neste projeto de formação de educadores/professores. É talvez esta a dimensão que marca efetivamente a diferença e o alcance de estar em contexto e (d)e vida e(m) formação em Évora, dando todo o sentido à realização de um ABP.

Em nosso entender, este curso pretende abranger o que é ser (e tornar-se) monodocente em trabalho escolar com crianças, porque alinha com entendimentos de um saber que se constrói na universidade, nas escolas, na vida, dando origem a ações profissionais socialmente necessárias, utilizando esta feliz expressão de Roldão (2017). No fundo, o que lemos também num texto nosso:

«Na busca do isomorfismo pedagógico como estratégia de transferência das aprendizagens da formação para a profissão, através da constituição de um projeto de formação claro e coerente para os educadores e professores monodocentes, demos conta da necessidade de aprofundar relações e trabalhos, com os colegas das diversas áreas e que participam nestes cursos. Se já conseguimos garantir, ao longo da formação, unidades curriculares centradas na monodocência, ainda nos falta ampliar a comunicação e articulação entre estas UCs e as Ucs da área de docência e das didáticas especificas disciplinares. Esta articulação torna-se particularmente necessária nos momentos da supervisão da PES e feitura dos seus relatórios. Só o constante diálogo, entre o todo e as partes, permite apreender "[...j o que está tecido junto [...] "(MORIN, 2000, p. 41). Utilizando as palavras de Leontiev (1987), importa em cada momento da formação não perder o motivo da atividade principal (ser educador/professor monodocente) para que as ações e operações que contribuem para a sua realização não percam significado mais abrangente». (Folque, Leal da Costa \& Artur, 2016: 223).

Reafirmamos palavras anteriores, robustecendo a ideia que nos quotidianos da formação, as ausências da voz de (futuras) educadoras/professoras sobre a pessoa quem são e sobre a sua (trans)formação são recorrentes. Devemos admitir que não há quimeras para interpretar e significar a sua existência, a direção que entendermos dar-lhe, nem caminhos certos para responder aos desafios de aprender esta profissão docente, ou qualquer outra. Porém, admitimos que a reflexão conjunta e as escritas de si podem ser uma 
das mediações possíveis para o fazermos, na medida em que «alimentam o nosso ganhar forma, para as reinvestirmos conscientemente» (Josso, 2002: 202).

\section{Como foi? - Um projeto com etapas, planeado e avaliado em conjunto}

\section{«(...) aquela fração real dos dedos juntos/ como para escrever cada palavra:/pegar ao alto numa coisa em estado de milagre: seja um copo de água,/ tudo pronto para que a luz estremeça: o terror da beleza, isso, o terror da beleza delicadíssima/ tão súbito e implacável na vida (...).»}

(Herberto Helder, in Servidões)

Qualquer projeto, individual ou coletivo, tem sempre uma pré-história, mas também tem horizontes. As palavras de Delory-Momberger (2006) permitem dar-nos o mote e concordar que «toda atividade humana, desde a mais rotineira até a mais excepcional, implica um horizonte de possibilidade, um espaço diante dela mesma que a conduz à existência e que lhe confere sua finalidade e sua justificação» (p.364). Consideramos essencial este dar conta de quais foram as nossas inquietações iniciais, o que nos moveu, o que fizemos no projeto do ateliê que todas promovemos, quais os nossos recursos, mas também até onde já nos levou o que desenvolvemos até ao momento. Porventura estes são aspetos que remetem a pesquisa biográfica para o que constitui «a dimensão ética da sua abordagem, ou seja, a preocupação de esclarecer as condições sobre as quais a fala de si pode constituir para o sujeito um vetor de apropriação de sua história e de seu projeto e contribuir dessa forma para uma perspetiva emancipatória das pessoas e dos grupos humanos» (Delory-Momberger, 2016: 146). E é desse processo integrado e integrador que aqui falamos, um processo que começou com a nossa consciência que «no processo de biografização, a pessoa que narra, embora não possa mudar os acontecimentos, pode reinterpretá-los dentro de um novo enredo, reinventado-se com ele» (Passeggi \& Souza, 2017).

Ao questionarmos as estudantes sobre como deveríamos fazer, ainda no final do ano letivo anterior, fomos conversando com as alunas em contextos informais, assim como participando em eventos científicos, para sucessivamente podermos compreender que narrar era uma atitude humana fundamental e que levar a sério essa atitude deveria passar não apenas por reconhecer a sua importância, mas por encontrarmos formas de configurar narrativamente a temporalidade da nossa experiência. Isso implicaria diferentes possibilidades de se apropriarem de instrumentos das mais diversas naturezas, incluindo os semióticos que nos permitem contar a vida, mas também escutar as crianças e alterar contextos. Acordámos que iniciaríamos o ABP no início do ano letivo de 2017-2018, abarcando o espaço-tempo da Prática de Ensino Supervisionada, quer em $1^{\circ}$ Ciclo, quer em Educação Pré-escolar e assim o designámos na medida em que seria, simultaneamente, um projeto de cada uma e de todas.

O tempo era importante, não apenas para nos organizarmos, mas porque configurar narrativamente a sucessão temporal da experiência seria, para todas nós, um desafio à emancipação e ao empoderamento. Seria importante ser assim, pois os contextos escolares em estágio não eram indiferentes e revelavam-se realidades muito diversas e suficientemente boas para superarmos interpretações culturais, sobre a escola, sobre ser aluno, sobre o que é ensinar ou sobre o que é aprender, ousando descortinar «quem sou e como me vou tornando educador/professor».

Fazer uso das narrativas como dispositivo pedagógico, porque se trataria de um ateliê biográfico que instituiria cada uma de nós como autora e caminhante, interessada no conhecimento que produz para si mesma, sobre si e sobre os outros e sobre o contexto social e histórico, refazendo o conhecimento a cada 
passo e podendo intervir com (re)construção de significados e com sentido (Alheit \& Dausien, 2000; Delory-Momberger, 2006, 2012, 2016; Ferrarotti, 2013; Passeggi \& Souza, 2017).

Combinámos fazer seis sessões, em conversas esclarecedoras e com toda a equipa docente, permitindo fazermos escolhas de encontros e momentos consentidos e informados por estudantes e professores da universidade, incluindo nós, autoras do texto, que participaríamos diretamente na ação. O planeamento sugeriu o seguinte:

Sessão 1 Conversa sobre o projeto e planeamento participado, integrado (e integrador) do ABP no tempo da Prática de Ensino Supervisionada (PES) e, portanto, correspondente a dois semestres letivos.

Sessão 2 Conversas e reflexões cruzadas, com proposta de escuta interior - Quem sou? Como cheguei aqui? O que é a escola (e o jardim de infância)? Qual é a minha posição e papel naquele lugar?

Sessão 3 Leituras cruzadas das narrativas escritas, conversas e reflexões partilhadas entre pares (incluiu as docentes). Identificação de vivências, encontros e momentos chave.

Sessão 4 Momento de síntese, em que cada formanda «se reconta», incorporando a escuta de voze(s) exteriores e tornando públicas as nossas vozes.

Sessão 5 Relatos cruzados a partir de releituras das escritas de si incorporando vivências na PES em Educação Pré-escolar.

Sessão 6 Identificação de aspetos que permaneceram, daqueles que alterámos, dos que queremos que permaneçam explicitando para quê e incorporando os contributos d(n)as reflexões semanais produzidas no âmbito da PES. (Re)Consrução de identidades através da reflexão e da escrita.

Deste planeamento inicial, e tal como qualquer projeto, houve necessidade de adequar alguns aspetos e momentos.

Iniciámos quando previsto, mas as datas foram alteradas a partir da segunda sessão, de acordo com possibilidades reais. Mas a maior alteração foi sugerir a redação da narrativa biográfica entre a segunda e a terceira sessão, mediante orientações escritas. A conversa em sala de aula tinha sido incipiente e a escrita precisava de orientação e tempo. Todas tivemos essa perceção e assim aconteceu. Enquanto dinamizadoras assumimos essa tarefa, organizando um documento orientador para a escrita da narrativa biográfica, que seguiu via e-mail para as estudantes, acordando um tempo para fazer e para a enviarem para nós e focando a sua atenção nos seguintes tópicos ${ }^{12}$ :

1. Eu, no lugar (escola) que habito Como cheguei a este «lugar»? O que trouxe e o que trago nas «minhas bagagens para fazer esta viagem»? Ou, quem sou e como cheguei até aqui, tornando-me educadora-professora? O que é para mim ser professora?

\footnotetext{
12 Estas orientações, enviadas por nós em novembro de 2017, foram acompanhadas de um texto inicial e final, esclarecendo por escrito o que poderiam precisar na reflexão de cada tópico. Não cabe neste artigo escrever o texto completo, mas consideramos que estes focos de reflexão foram cumpridos e constituíram o principal impulso da escrita da narrativa de cada estudante. Foram-nos enviadas em janeiro de 2018, mês em que a atividade letiva estava em pausa e no qual voltámos a encontrarmos para a sessão 3, após termos recebido as narrativas. Todas as estudantes participaram, mas em nenhum momento foram obrigadas a fazê-lo.
} 
2. Que lugar é este? Como é a escola? E o lugar? O que observo? O que vejo/sinto/penso sobre o que observo e o que mais me marcou? Que confronto entre a realidade e a expectativa?

3. Que objetos (observações, metodologias, saberes, currículo, projetos, etc) convoco e mobilizo para dar vida a este lugar que habito e no qual que me movo? Como disponho e uso estes «objetos»?

4. Quem são os «outros» (dentro fora de mim) que habitam comigo este lugar? Como (com)vivo com eles e como os perceciono?

Nós, as docentes, fizemos a leitura de todas e anotámos as ideias-chave que emergiram nas narrativas, antes do encontro presencial na sessão três e que partilharemos adiante neste texto.

A terceira sessão permitiu a leitura cruzada, a conversa e a reflexão partilhada. No entanto, percebemos a dificuldade de um processo comunicacional mais participado por todas nós. Tal significa que apesar de todas terem falado sobre si e sobre as colegas, ressaltaram as nossas vozes na mediação e na conversa.

As restantes sessões ainda não aconteceram. Mas em fevereiro de 2018, tornámos públicas as nossas vozes na comunicação oral que deu origem a este texto. Na sessão quatro apenas três estudantes estiveram presentes, sugerindo adiarmos os momentos de encontro. Nos tópicos que se seguem, partilhamos o que já conhecemos.

\section{Narrativas emergentes - pensando sobre a própria vida}

\section{«Para mim, o importante é compreender. Para mim, escrever é uma questão de procurar essa compreensão, parte do processo de compreender».}

(Hanna Arendt, 2001)

Acreditar que a preocupação com a educação bumana atribui à pesquisa biográfica a responsabilidade particular, «não é apenas de ordem científica, mas também ética e política e que é também o vetor pelo qual os seres humanos acessam a um saber e a um poder deles mesmos que lhes dão a capacidade de se desenvolver e de agir enquanto "sujeitos" no meio dos outros e no seio da cidade». (Delory-Momberger, 2016: 145), justifica o que aqui partilhamos em seguida.

Da leitura/reflexão partilhada das narrativas escritas pelas alunas, foi possível evidenciar os aspetos em torno dos quais as mesmas se desenrolavam. Assim, as narrativas aparecem centradas sobretudo: na forma como cada uma chegou a este «lugar/ escola e na construção de significados do que é ser-se educadora/professora». A leitura fez-nos também pensar como o hoje dificulta um distanciamento da reflexão face ao que está a ser vivido, talvez porque tudo parece estar demasiado presente.

De salientar ainda, expressões, conceitos e dimensões formativas que se destacam e que foram utilizadas na forma como as estudantes se pensam, parecendo revelar a apropriação de discursos e orientações da matriz que identificámos na conceção do percurso profissionalizante e que, talvez assim a legitimam. Apresentamos de seguida, alguns desses aspetos emergentes a partir das releitura(s) cruzadas, partilha e conversas entre pares. As transcrições estão identificadas, com garantia do anonimato de cada estudante que verbalizou a escrita. A cada nome foi atribuído um código com duas letras que lhe corresponde.

Um desses aspetos prende-se com os caminhos da construção do desejo de se ser educadora/professora. Dizendo-se, algumas escreveram nas suas narrativas, e confirmaram nas conversas, que sempre desejaram ser educadoras/professoras: 
«As minhas brincadeiras sempres se desenvolveram em torno da escola e do cuidado com as crianças». (CD).

«Desde que me lembro que quero serprofessora ... desde cedo que senti um entusiasmo pela aprendizagem e pelo poder ensinar, e por isso, nunca me vi a ser outra coisa». (SA).

Ou que nunca pensaram em ser educadoras/professoras:

«Nunca me passou pela cabeça ser professora.(...). N No $^{\circ}$ ciclo tive uma professoar o menos correta possivel que me intitulou como uma criança com dificuldades de aprendizagem, im aginam como é dificil (...) sentirmo-nos inferiorizados sentir que não prestamos para nada? Mais tarde tive uma professora diferente que era carinhosa e ...o mais imp era que nos ouvia... Só mais tarde decidi que queria ser educadora, pois en gostava de crianças e elas pareciam sempre adorar-me». (BT).

Nesse caminho de construção do seu ser educadoras/professoras, destacam-se momentos que marcaram a construção deste querer ser educadora/professora:

"Lembro-me bem da minha educadora e dos momentos bons que vivia com elal do meu professor do $4^{\circ}$ ano e do prazer que tinhamos em aprender. Acho que foi aí que comecei a querer também ensinar». (AB).

"Um professor ... que tinha um método de ensino que me cativou e me fez desenvolver o desejo de ensinar (...). Mais tarde o trabalhar numa ludoteca, despertou ainda mais o meu desejo de lecionar e aprender com crianças». (AC).

«No $4^{\circ}$ ano tive uma das professoras que me marcou mais, pois era divertida e propunha muitas tarefas em grupo. Como eramos um grupo pequeno de crianças, eramos apenas oito, fizemos projetos todos juntos. Lembro-me de pensar, durante este ano, que quando crescesse queria ser uma professora como ela, animada e que fizesse as crianças gostarem da escola». ( $S A$ )

Outro dos aspetos que emerge como fundamental passa pelos caminhos da construção do desejo de se ser educadora / professora na formação universitária. E aí, no que é dito e nas expressões usadas para o dizer é possível perceber a forma como o modelo de formação está a ser apropriado pelas alunas. É assim que aparece também a importância dada ao contacto continuado com os contextos da prática profissional:

"Após a entrada na Licenciatura em Educação Básica, principalmente após as unidades curriculares de Iniciação à Prática Profissional em Pré-Escolar e $1^{\circ}$ Ciclo do Ensino Básico, percebi que era realmente esta a professar que queria seguir no futuro». (CD).

«Fui colocada no curso de EB, que não era a minha primeira escolha. ... mas através dum projeto numa u.c que envolvia crianças do $1^{\circ} \mathrm{c}$, e que me obrigou a planear, definir objetivos e pô-los em prática, fez-me ver o que era o dia a dia duma prof. Mais tarde o estágio e os desafios que me colocou, fizeram-me sentir realizada e perceber que o que quero mm é contribuir para a formação e aprendizagem daquelas crianças». (AC).

"Foi no estágio que pela primeira vez. deixei de ser a X e comecei a ser a professora X, ensinei, dei a minha primeira aula ou seja foi aqui tive a oportunidade de percecionar o men futuro profissionals. (AS). 
«Nopresente semestre estive com uma turma bastante complicada na escola $X$ mas que se transformou num desafio profissional e pessoal. No decorrer da pratica senti-me realizada, com a certeza que é mesmo o que quero para a minha vida profissional». (AP).

E evidenciaram a importância dos educadores/professores cooperantes, remetendo-nos para o lugar da reflexão:

«As partilhas realizadas entre colegas e as partilhas e diálogos com a minha professora cooperante foram muito construtivos na minha formação». (VS).

«Ao refletir sobre a prática da educadora, aprendi não só alguns métodos e estratégias de dinamizar a sala, (...), como também desenvolvi em mim um olhar critico e uma curiosidade entusiasmante sobre este modelo, interligando-o com as minhas atitudes como futura educadora. A realização do caderno de formação, permitiu a minha adaptação ao contexto educativo, mas foi também através dele que consegui manter e estabelecer uma relação de comunicação e de trabalho com a educadora. A prática reflexiva e dialogada com a educadora deste contexto proporcionou-me a oportunidade de aprender sobre a profissão, tornando-me mais consciente sobre o que observava na sala. Foi também através do seu feedback - muitas vezes em forma de pergunta, fazendo-me pensar e refletir sobre o meu próprio pensamento». (CP).

«Nessas reflexões, entre o que acontecia e o que a investigação cientifica revelava sobre os momentos, podia consciencializar-me mais sobre as minhas ações e futuras intervenções, orientando, deste modo, as planificações semanais (...) A reflexão permanente sobre a minha prática foi determinante para 0 meu desenvolvimento pessoal e profissionalis. (VS).

«... foi ao observar e refletir sobre o contexto me que me encontrava, inspirada no modelo pedagógico do MEM, que comecei também a refletir criticamente sobre o meu papel no futuro e a apropriar-me eu pp do modelo». (CP).

Sugerem também a importância do trabalho em cooperação e da partilha em grupos de profissionais:

«Ter unidades curriculares, onde a construção do meu conbecimento, foi realiz̧ada em cooperação com as minhas colegas de formação, através da pesquisa e partilha foi determinante para a minha conceşão sobre aprendizagem e educação (...) O facto de não nos isolarmos e de trabalharmos de forma cooperativa, permitiu-me constatar a riqueza que resulta da união bumana, em prol de um sentido». (VP).

«Faltava-me partilhar, faltava-me falar, faltava-me ter alguém próximo que, para além de dizer "Parabéns pelo teu trabalho!', compreende-se as minha ideias, os meus princípios e valores, percebese a grande transformação pela qual eu estava a passar. Imp de partilhar a experiência que tive no jardim-de-infância num Congresso do MEM, onde tive oportunidade de sentir que pertenço a algum lugar e que posso ser ouvida». (CP).

\section{Algumas metáforas para finalizar ... ou concluindo sem terminar!}

«A narrativa é o momento primeiro do processo de produção de uma história de vida, que só começa a partir do trabalho de reflexão (de retorno sobre si) e de análise feito sobre a narrativa).

(Delory-Momberger, 2006: 363)

Nas narrativas pudemos também identificar metáforas que nos falam da forma como vivem os ser -se educadora/professora. Algumas dessas metáforas remetem-nos para o cuidar, olhado a partir do afeto: 
"... sentir-me amada era o que mais me importava e realizava. Quero ser uma educadora/professora carinhosa e atenciosa como a educadora que tive, docil e atenciosa como ... Foi a forma como elas cuidaram de mim (...)». (MC).

E também a necessidade do cuidar para tornar feliz:

"Com o passar do tempo, fui percebendo que as crianças eram um encanto para mim. Chegados aos meus 12 anos, nasceu o meu irmão. A partir de então, a minha capacidade de cuidar (...), foi aumentando e fui percebendo que, um dia mais tarde, gostaria de trabalhar com crianças, ensinando-lhes o que de melhor sei, dando-lhes o que de melhor tenho para dar, proporcionar-lhes aprendizagens significativas e sobretudo... ver as crianças felizes. Isto faz-me feliz e faz-me sentir realizada». (AB).

Outras metáforas falam-nos da docente como aquela que encaminha, permitindo a apropriação:

«O professor é aquele que ajuda a encaminhar, fornecendo todos os materiais necessários para que, futuramente, a criança se aproprie dos mesmos». (VS).

E permitir aprender de forma participativa e ativa:

«Durante as minhas práticas, preocupei-me sobretudo que as crianças fossem os agentes principais na construção do seu conbecimento, pois tinha como experiência pessoal, que essa era a metodologia mais significativa nas aprendizagens. Construir o nosso conhecimento, como experimentei ao longo da formação permite-nos atribuir mais significado às nossas aprendizagens». (CP).

Ou ainda do preparar para a vida, incentivando a curiosidade e a autonomia a partir de sentidos de fazer e de aprender, de interesses e/ou vivências das crianças:

"Outros momentos da minha infância que penso que infuenciam a forma como eu quero transmitir conbecimento às crianças, prende-se com o facto de eu gostar de realizar trabalhos manuais. Desde pequena que assisti a programas televisivos que ensinavam técnicas de artes plásticas e eu, por iniciativa própria, queria realizar essas técnicas com os materiais que tinha disponiveis. (...), nunca ninguém me "obrigou" a aprender a fazer estas coisas, apenas tive curiosidade. Talvez.por isso quero ser uma por ${ }^{a}$ que incentiva as crianças a ter curiosidade e a ser autónoms. Quero ser uma professora que dá oportunidade às crianças de aprenderem a trabalhar com diferentes materiais e a criar obras que tenham objetivos, que não seja apenas expor nas paredes e nos corredores da escola. (...) penso que o meu objetivo, enquanto professora, será não só preparar os alunos para uma vida académica, mas também para a vida. (...) e que, se possivel, possam ser autónomas». (SA).

Metáforas com que concluímos, mas sem finalizar, porque estas nos remetem para uma identidade profissional em construção, na qual aparece ainda em processo de integração o ser educadora e professora:

«No terceiro ano da licenciatura ... até a este momento eu sempre achei que seria mais realizada a lecionar primeiro ciclo, no entanto, com o contacto da educadora cooperante na observação e semana de intervenção, foi uma aprendizagem tão grande e esta consegui passar-me a sua paixão com que trabalhava que eu fiquei com uma visão de educadora muito diferente daquela que eu tinha, passando também a adorar esta parte da nossa profissão». (JP).

Concluindo, sem terminar, percebemos que uma compreensão hermenêutica não é dada, precisa de «um distanciamento crítico e uma capacidade de 'leitura' da qual o narrador, envolvido em sua narrativa, 
não dispõe voluntariamente. É esse espaço de objetivação crítica e de compreensão que a proposta de formação dá acesso e que o grupo de formação realiza coletivamente» (Delory-Momberger, 2006: 363). Portanto, reconhecemos que este texto será ainda um starting point para a etapa final deste ABP. Combinámos com as estudantes que a partilha e divulgação desta escrita solicitará a cada estudante uma reescrita final da narrativa biográfica da sua formação. Simultaneamente, pensamos que esse será o momento de compreendermos o quanto foi importante este ateliê na aproximação entre as protagonistas, todas nós, e como esbatendo assimetrias teremos aproximado discursos sobre a identidade do profissional que pensamos poder ser a de educadora/professora.

Certas das metamorfoses que aconteceram no interior de cada uma pela via desta atividade biográfica, novas questões emergiram e ficarão por responder. Por exemplo, como aconteceu todo o processo interior que marca uma (trans)formação permitida pelas histórias de vida? Ou, por outras palavras, manteremos o interesse na pesquisa biográfica em busca de uma melhor compreensão dos processos vividos pelas próprias estudantes na formação de si próprias num trabalho com narrativas?

Finalizando, pensamos que este pode ter sido um primeiro passo para a utilização de histórias da vida numa formação com narrativas biográficas na Universidade de Évora, permitindo-nos continuar, ou mesmo avançar, nomeadamente para o campo da formação de outros profissionais que não apenas educadores/professores. Falamos de aprofundar o lugar das narrativas biográficas «na produção interior do mundo exterior» (Delory-Momberger, 2016: 141) durante a formação inicial de educadores/professores e de estender este trabalho a outros profissionais do cuidar, nomeadamente da Saúde. Eventualmente, tencionamos incluir este trabalho num projeto internacional mais amplo sobre Saúde, Educação e Cuidado, que já estamos a conceber. Assim, julgamos tornar possível ampliar conhecimentos e dar contributos para melhor se compreender o lugar das narrativas no pensar e formar para o cuidar, abarcando o panorama internacional.

No fundo participarmos na mudança da formação para mudar a profissão, a partir do conhecimento (Nóvoa, 2017), mas daquele que vamos construindo em projetos que movem interesses mútuos, «sustentados numa revolução narrativa em contra la mera ilusión biográfica» (Passeggi, 2015: 84). Portanto, também contribuirá para a afirmação da pesquisa biográfica, enquanto formadores comprometidos com as pessoas sobre e com quem investigamos, mas também com aquilo que a narrativa faz e/ou possibilita. Por um lado, porque os trabalhos na docência e na investigação nos têm levado a uma construção partilhada de sentidos para «entender como a narrativa ao mesmo tempo produz e permite vislumbrar a construção singular que um indivíduo faz de uma existência e de uma experiência, elas também singulares, que integram e se apropriam de elementos coletivos» (Delory-Momberger, 2016: 142). Por outro lado, percebemos nas narrativas quanto a condição de futura educadora/professora exige reflexões sobre múltiplas identidade(s) em construção tendo em conta o processo, os contextos e a pessoa em formação. Acompanhar e refletir em momentos de formação profissional universitária, pode ser um caminho que deixa carrilar projetos (d)e vida e identidades que se (re)constroem transgredindo posições e fomentando disposições. Pensamos aqui, sobretudo, sobre os silêncios acerca de quem são afinal estes profissionais educadores/professores, como se formam e qual pode ser o papel da universidade e de nós professores, investigadores e formadores nessas trajetórias identitárias. Mas pensamos igualmente noutros desafios contemporâneos que abrem espaço a silêncios profissionais, também eles narrativas que deveremos escutar, tendo em conta o cuidar para formar e uma ecologia dos saberes. 


\section{Referências bibliográficas}

Abraham, Ada (1982). Le monde interieur des enseignants. Issy-les-Moulineaux:E.P.A.

Abraham, Ada (1989): "Une approche centrée sur la personne de l'enseignant". Educatión et Pedagogie, 1, 23-32.

Alheit, Peter (1999): "On a contradictory way to the 'Learning Society': a critical approach". Studies in the Education of Adults, 31 (1), 66-82.

Alheit, Peter (2009): "Biographical Learning - within the new lifelong learning discourse” em Knud Illeris (ed.): Contemporary Theories of Learning. Learning theorists ... in their own words. London: Routdlege.

Alheit, Peter e Dausien, Bettina (2000): “Biographicity' as a basic resource of lifelong learning” em Peter Alheit, et al., (Dir.): Lifelong learning inside and outside schools. Roskilde University, Universitat Bremen and Leeds University.

Alheit, Peter e Dausien, Bettina (2006): "Processo de formação e aprendizagens ao longo da vida". Revista Educação e Pesquisa, São Paulo, v. 32 (1), 177-197, jan./abr.

Arendt, Hanna (1958). A Condição Humana. Tradução de Roberto Raposo. Lisboa: Relógio de Água, 2001.

Botinet, Jean Pierre (2017): "Des sciences de la formation peuvent-elles exister et avec quelles spéci cités épistémologiques?”. Revue Savoirs, 1 (13), 135-147.

Breton, Hervé (2018). "Enquete sur les effets vecus au cours de l'activite biographique: vers une perspective micro-phenomenologique pour penser l'hermeneutique du soi". Revista Brasileira de Pesquisa (Auto) Biográfica, Salvador, v. 03 (07), 274-289.

Couveiro, Cristel; Leal da Costa, Conceição e Folque, Maria Assunção (2013): "Sendo educadora-professora - aprendizagens de qualidade (re)construindo saberes" em Lourdes Mata, et al., (ed.): Atas do XIII Colóquio Internacional de Psicologia e Educação. Lisboa: ISPA.

Clandinin, Jean e Connelly, Michael (2000). Narrative inquiry: experience and story in qualitative research. San Francisco: Jossey Bass.

Clandinin, Jean e Connelly, Michael (1995). “Teachers' professional knowledge landscapes: secret, sacred, and cover stories" em Jean Clandinin e F. Michael Connelly (org.): Teachers'Professional Knowledge Landscapes. Columbia: Teachers College, Columbia University.

Delory-Momberger, Christine (2005). Histoire de vie et recherche biographique en éducation. Paris: Economica Anthropos.

Delory-Momberger, Christine (2006): "Les ateliers biographiques de projet [Formation and socialization: The project biographical workshops]”. Educaşão e Pesquisa, 32 (2), 359-371.

Delory-Momberger, Christine (2012): “Abordagens metodológicas na pesquisa biográfica”. Revista Brasileira de Educação, 17 (51), 523-536.

Delory-Momberger, Christine (2016): “A pesquisa biográfica ou a construção compartilhada de um saber no singular”. Revista Brasileira de Pesquisa (Auto)Biográfica, 1 (1), 133-147.

Engeström, Yrjö (2001): "Expansive Learning at Work: Towards an Activity-Theoretical Reconceptualisation". Journal of Education and Work, 14(1), 133-156. 
Ferrarotti, Franco (2013): "Partager les savoirs, socialiser les pouvoirs". Entrevista. Christine DeloryMomberger. Le sujet dans la Cité. Revue internationale de recherche biographique, v.4, 19-27.

Flores, Maria Assunção; Hilton, G. e Niklasson, L. (2010): "Reflexão, profissionalismo e qualidade dos professores” em Maria Palmira Carlos Alves e Maria Assunção Flores (Org.): Trabalho Docente, Formação e Avaliação. Clarificar conceitos, fundamentar práticas. Lisboa: Edições Pedago.

Folque, Maria Assunção; Leal da Costa, Conceição e Artur, Ana (2016): "A formação inicial e o desenvolvimento profissional de educadores/professores monodocentes: os desafios do isomorfismo pedagógico" em C. H. A Corrêa, L. I. P. Cavalcanti e M. F. Bissoli (Org.): Formação de professores em perspectiva. Manaus: EDUA.

Hall, Stuart (2006). A identidade cultural na pós-modernidade. Rio de Janeiro: DP\&A.

Josso, Marie Christine (2002). Experiências de vida e formação. Lisboa: Educa.

Leal da Costa, Conceição (2015). Viver construindo mudanças: a vež e a voz de professores. Contributo para os estudos da aprendizagem e desenvolvimento dos professores. Tese de Doutoramento. Évora: Universidade de Évora.

Leal da Costa, Conceição e Cavalcante, Ilane (2017): “Alteridades(s), escritas de si e reflexão: olhares cruzados sobre a formação de professores em Portugal e no Brasil”. Revista Brasileira de Educação de Jovens e Adultos, 5 (10), 108-126.

Leal da Costa, Conceição e Nunes, Sandra (2016): “Tornar-se Educadora/Professora - Palavras que contam como foi!". Educação e Contemporaneidade, 25 (47), 119-136.

Lipiansky, Edmond-Marc; Taboada-Leonetti, Isabelle e Vasquez, Ana (1990). "Introdutión à la problematique de l'identité” em Carmel Camilleri et al., (Org): Stratégies identitaires. Paris:Puf

Niza, Sérgio (2009): “Contextos cooperativos e aprendizagem profissional: a formação no movimento da escola moderna" em João Formosinho (ed.): Formação de professores: aprendizagem profissional e acção docente. Porto: Porto Editora.

Nóvoa, António (1992). Os professores e a sua formação. Lisboa: D. Quixote,

Nóvoa, António (2004). Currículo e Docência: A pessoa, a partilha, a prudência. http:/ / repositorio.ul.pt/bitstr eam/10451/4816/1/8575161121_1_11.pdf, acessado em 12 de março de 2018

Nóvoa, António (2017): "Firmar a posição como professor, afirmar a profissão docente". Cadernos de Pesquisa, 47 (166), 1106-1333.

Passeggi, Maria da Conceição (2011). "A experiência em formação”. Revista Educação. Porto Alegre, v. 34, n. 2, 147-156, maio/ago.

Passeggi, Maria da Conceição (2016). "A pesquisa (auto)biográfica: por uma hermenêutica descolonizadora". Coisas do Gênero, 2 (2), 302-314.

Passeggi, Maria da Conceição e Souza, Elizeu Clementino (2017). "O Movimento (Auto)Biográfico no Brasil: Esboço de suas Configurações no Campo Educacional". Investigación Cualitativa, 2 (1), 6-26. DOI: http://dx.doi.org/10.23935/2016/01032 
Pineau, Gaston (2012): “Traces de vie et vie des traces” em Martine Lani-Bayle et Éric Milet (Org.): De láutre côte du récit et de la resilience. Lyon: Chronique Sociale.

Pineau, Gaston e Le Grand, Jean Louis (2007). Les histoires de vie. Qui sais je? Paris: Puf.

Roldão, Maria do Céu (2017): “Conhecimento, Didática e Compromisso: o triângulo virtuoso de uma profissionalidade em risco”. Cadernos de Pesquisa, 47 (166), 1134-1149.

\section{Notas biográficas}

Conceição Leal da Costa es graduada en Enseñanza de la Física y la Química por la Universidad de Évora (Portugal). Máster en Administración Educativa. Doctorado en Ciencias de la Educación por la Universidad de Évora, donde es profesora auxiliar en el Departamento de Pedagogía y Educación. También es investigadora del Centro de Investigação em Educação e Psicologia (CIEP|UE) y del Comprehensive Health Research Center (CHRC).

Constança Biscaia es graduada en Psicología por la Universidad de Évora, donde ejerce como profesora asociada del Departamento de Psicología. Directora del Serviço de Extensão à Comunidade em Psicologia (SEC-PSI).

Andrés Argüello Parra es graduado en Educación por la Universidad de la Salle (Bogotá, Colombia) y doctor en Pedagogía por la UNAM. Es docente de Ciencias Sociales en la Universidad de Santo Tomás de Colombia. Investigador del Grupo HISULA; Colaborador del CIEP|UE. 